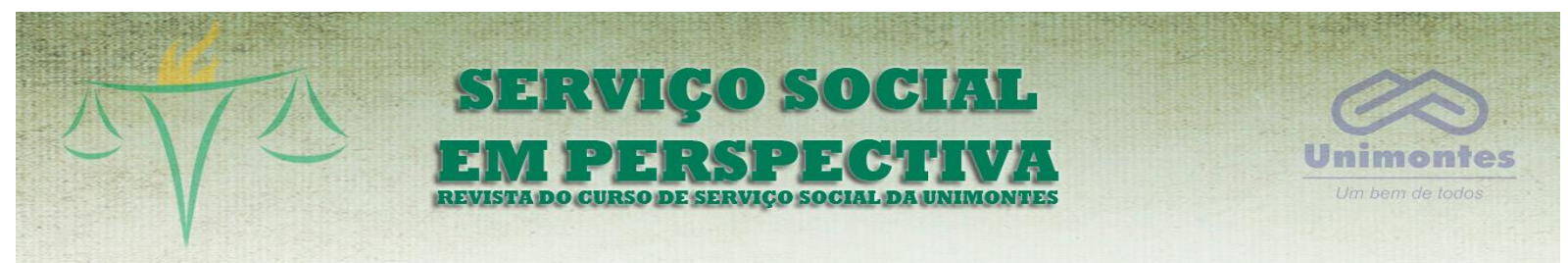

\title{
ESTÁGIO SUPERVISIONADO NO INSTITUTO FEDERAL DO RIO GRANDE DO NORTE E A PRECARIZAÇÃO DO TRABALHO DO/A ASSISTENTE SOCIAL NA ASSISTÊNCIA ESTUDANTIL
}

\section{SUPERVISED INTERNSHIP AT THE FEDERAL INSTITUTE OF RIO GRANDE DO NORTE AND THE PRECARISATION OF THE WORK OF THE SOCIAL WORKER IN THE STUDENT ASSISTANCE}

Resumo: O presente artigo é resultante do processo de vivência em campo de estágio na área da educação. Sendo assim, no decorrer do texto existe um ordenamento de reflexões e análises que foram feitas ao longo desse processo a partir do cotidiano profissional vivenciado entre maio de 2014 a junho de 2015 no IFRN Reitoria, situado na zona Sul de Natal, no território do bairro Tirol. Porém, a experiência nos faz refletir sobre elementos conjunturais que estamos vivenciando atualmente com os desmontes na politica de educação, sobretudo no contexto da COVID-19. Com isso, a produção textual problematiza e analisa as configurações do campo e, por conseguinte, aponta as condições que se apresenta a política de Assistência Estudantil no IFRN Reitoria, as quais possuem raiz em um passado histórico e que este traz consigo diversos rebatimentos aos estudantes daquela instituição nos tempos atuais. Do mesmo modo, expõe um debate critico sobre os desafios e limites que têm se apresentado ao exercício profissional do/a Assistente Social na política de Educação, mais precisamente no âmbito do IFRN Reitoria, bem como a explanação sobre os entraves e dificuldades à materialização equânime da politica de assistência estudantil como um direito das/os estudantes.

Palavras-Chaves: Estágio supervisionado; Assistência estudantil; Serviço Social

Abstract: This article is the result of the process of living in an internship field in the area of education. Therefore, in the course of the text, there is an ordering of reflections and analyzes that were made throughout this process based on the professional routine experienced between May 2014 and June 2015 at IFRN Reitoria, located in the southern area of Natal, in the neighborhood's territory Tirol. However, the experience makes us reflect on conjunctural elements that we are currently experiencing with the dismantling in the education policy, especially in the context of COVID-19. With this, the textual production problematizes and analyzes

\footnotetext{
${ }^{1}$ Assistente Social. Mestra em Serviço Social pela Universidade Federal do Rio Grande do Norte. alalcindo@gmail.com
} 
the field configurations and, therefore, points out the conditions presented by the Student Assistance policy at IFRN Reitoria, which are rooted in a historical past and which this brings with it several repercussions to students of that institution today. Likewise, it exposes a critical debate about the challenges and limits that have been presented to the professional practice of the Social Worker in Education policy, more precisely within the scope of the IFRN Rectory, as well as the explanation of the obstacles and difficulties to equitable materialization of student assistance policy as a right of students.

Key words: Supervised internship; Student assistance; Social service

\section{INTRODUÇÃO}

Segundo lamamoto (2010), as tensões e contradições situam-se no protagonismo profissional, embasada pela relativa autonomia profissional, que ainda que os profissionais disponham no mercado de trabalho de autonomia na condução de suas atividades, as/os empregadoras/es articulam um conjunto de condições que informam o processamento da ação e condicionam a possibilidade de realização dos resultados projetados, estabelecendo desta forma as condições sociais em que ocorre a materialização do projeto profissional em seus espaços ocupacionais. Subordinando a profissão ao mercado e sujeitando a/o assistente social ao trabalho alienado.

Dessa maneira, observa-se que o cenário que nos é colocado cotidianamente no âmbito do estágio é permeado de retração de direitos sociais e agravamento da desigualdade social, uma vez que a oportunidade de acesso aos programas, projetos e ações não é igualitária, pois a procura sempre é maior que oferta de vagas e consequentemente a demanda reprimida é altíssima. Então, é nítido que os programas ao mesmo tempo em que incluem, excluem outras/os estudantes, isto é, a seletividade está como um marco principal no acesso das/os estudantes aos programas, dificultando o acesso aos seus direitos. Então, o trabalho $\mathrm{da} /$ do assistente social possui diversos limites e contradições, principalmente no que diz respeito ao planejamento equânime do recurso financeiro destinado as ações da assistência estudantil. 
Assim, observa-se que esta demanda reprimida muitas vezes pode se concretizar na evasão escolar, uma vez que a/o aluna/o não possui condições de frequentar o ambiente escolar, devido a sua situação socioeconômica, cultural, geográfica ou mesmo questões referentes aos encaminhamentos didáticos pedagógicos, que não levam em consideração o histórico educacional daqueles estudantes no que diz respeito ao processo de ensino-aprendizagem, com uma educação básica fragilizada, impedindo um bom rendimento escolar em uma instituição de excelência como o IFRN.

Por sua vez, foi observado ao longo do processo de estágio que a/o assistente social torna-se uma/um executora/or terminal de politicas da assistência estudantil, se detendo em estabelecer os critérios de elegibilidade dos programas e priorizando o seu tempo para fazer as seleções dos inscritos. Com isso, acaba por apresentar em seu exercício uma dimensão burocrática e administrativa, na qual a atuação se torna limitada e limitadora, já que as demandas institucionais se tornam mais evidentes do que as profissionais. Por isso, vale enfatizar que a demanda institucional difere da demanda profissional porque elas contem propostas diferentes.

A demanda profissional prevê a mediação de primeira ordem como categoria essencial da prática, porque ela trabalha com a complexidade respondendo a determinantes variados, penetrando no tecido social, movendo-se nas várias instâncias das políticas sociais, dos programas sociais, das franjas institucionais ligadas tanto à sociedade civil organizada, quanto ao aparato institucional do Estado, isto é, busca uma análise que preza pelas diversas determinações da questão social.

Além disso, é perceptível a sobrecarga de atividades que é colocada para as/os assistentes sociais nos espaços sócio ocupacionais, onde o profissional deve exercer múltiplas funções no seu ambiente de trabalho e, muitas vezes é chamado a atuar em situações que não são de sua competência, o que se concretiza na precarização do trabalho do assistente social, já que este se sente coagido a atender uma demanda que não é da sua alçada, para atender os objetivos 
meramente institucionais. Ou seja, a/o profissional, termina submetido aos objetivos institucionais, esquecendo-se de quais são os seus objetivos profissionais.

E se pensarmos nesse contexto de pandemia da COVID- 19 a situação tem se agravado, pois o assistente social está realizando o trabalho remoto para algumas demandas uma vez que segundo o CFESS a orientação é que aos/às profissionais negociem coletivamente junto às chefias o revezamento das escalas de trabalho, possibilitando a redução de presença física nos serviços sem o comprometimento do atendimento à população.

Nesse sentido, no cenário atual do governo Bolsonaro observa-se a grande desregulamentação das leis trabalhistas, o que faz o trabalho das/dos assistentes sociais ficar cada vez mais fragilizado, onde são detectados diversos vínculos empregatícios e a perda dos laços entre a/o profissional e usuária/o, profissionais trabalhando em locais com condições insalubres dificultando o seu fazer profissional e com longas jornadas de trabalho para receber em troca o seu salário e que por sua vez é bastante criticado por ter um valor baixíssimo a depender do campo de trabalho. E uma demonstração desse teor de retração de direitos é a publicação da Medida Provisória $n^{\circ}$ 927/2020, a qual flexibiliza as relações e os contratos de trabalho no país. Essa proposta já ventilava na grande imprensa, como uma possível solução para a manutenção dos postos de emprego durante a propagação do Covid19. A MP parece desmontar os processos de segurança e saúde do/a trabalhador/a, a fiscalização das relações trabalhistas no país e o trabalho remoto de estagiários/as.

\section{O CONTEXTO DO IFRN E O SERVIÇO SOCIAL}

O IFRN é uma instituição de ensino que tem como função social ofertar educação profissional e tecnológica - de qualidade referenciada socialmente e de arquitetura político- pedagógico capaz de articular ciência, cultura, trabalho e tecnologia - comprometida com a formação humana integral, com o exercício da cidadania e com a produção e a socialização do conhecimento, visando, sobretudo, a transformação da realidade na perspectiva da igualdade e da justiça sociais. 
Desse modo, podemos inferir que o IFRN é uma instituição que tem um processo histórico evolutivo, com um amadurecimento de ensino que o qualifica como um importante espaço de formação, com ações amplas e articuladas com diversas áreas do conhecimento, sendo o serviço de assistência estudantil, uma área essencial para se estabelecer relações de desenvolvimento educacional, humano e social.

Com isso, o Serviço Social do IFRN pode estar inserido na DIGAE (Diretoria de Gestão de atividades estudantis), COAES (Coordenação de atividades estudantis) ou DIAES (Diretoria de atividades estudantis), esta atuação dependerá da particularidade do campus que este profissional estará inserido.

Destarte, a DIGAE, local de estágio, tem como objetivo pensar, elaborar, implementar e avaliar a Política de Assistência Estudantil como instrumento de abertura e acesso aos direitos sociais para permanência dos alunos na instituição, através de programas capazes de atender a demanda estabelecida em função de alunas/os que tenham um perfil socioeconômico diagnosticado sob o viés da vulnerabilidade. Inserindo-se no espaço de proposição de políticas públicas, o órgão compreende um espaço de coordenação e monitoramento de como se desenvolvem as atividades do Serviço Social de todos os campi do IFRN. Assim, a DIGAE é o órgão responsável pela gerência das políticas de assistência ao estudante, onde a execução é majoritariamente atribuída pelos campi, cada qual com sua autonomia.

As/os usuárias/os do Serviço Social da DIGAE são as/os participantes do programa de iniciação profissional, as/os que encontram-se inseridas/os ou aquelas/es que buscam ingressar nesta ação da assistência estudantil, podendo ser alunas/os do ensino técnico integrado, subsequente ou de nível superior que possuam vulnerabilidade social.

Dessa forma, as demandas que chegam para o Serviço Social são: Acompanhamento da execução financeira dos campi; Elaboração de relatórios financeiros a respeito da execução do orçamento planejado, bem como os relatórios de estudantes atendidas/os e não atendidas/os, em todos os serviços e programas da assistência estudantil, Elaboração de editais; Visitas domiciliares; Entrevistas para seleção do programa de iniciação profissional que atuarão na Reitoria; 
Reuniões com as/os bolsistas e profissionais (coordenadoras/es); Realização de encontros sistêmicos com as/os coordenadoras/es de atividades estudantis, isto é, assistentes sociais, psicólogas/os e as/os profissionais da saúde para avaliar as políticas e propor; Acompanhamento dos atendimentos registrados no SUAP pelas/os coordenadoras/es e assistentes sociais; Acompanhamento dos dados sócio-econômicos das/os estudantes; Efetuar ligações para os campi em busca de obter respostas sobre questionamentos e esclarecer dúvidas; Acompanhamento do desenvolvimento acadêmico dos bolsistas de iniciação profissional da Reitoria; Planejamento participativo para os recursos das ações estudantis; Elaboração do PDI (Plano de desenvolvimento interno) juntamente com as/os outros profissionais; Encaminhamento de e-mails; Elaboração de regulamentos para os programas da assistência estudantil; Doação de fardamento escolar; Dialogo com outros institutos; Acompanhamento da lista de estudantes participantes dos programas de iniciação profissional para fins de seguro de vida. Contudo, nesse momento essas atividades citadas estão sendo readequadas segundo às condições necessárias de isolamento social para conter o coronavírus, de modo a resguardar as/os profissionais e as/os estudantes das instituições de ensino.

\section{A POLITICA DE ASSISTÊNCIA ESTUDANTIL DO IFRN}

De acordo com os documentos do IFRN, a assistência estudantil é concebida como parte do processo educativo e configura-se como direito social dos estudantes, por meio de garantia do direito a educação pública de qualidade, na perspectiva de democratizar o acesso, a permanência, e o êxito escolar dos estudantes, sendo implementada em dois eixos de atuação: ações de atendimento universal e ações de atendimento para grupos sociais específicos. (IFRN, 2014)

As ações de atendimento aos grupos sociais específicos são construídas por programas, projetos e serviços, bem como o programa de alimentação, auxílio transporte e programa de iniciação profissional, fomento ao EJA. Assim, estas ações tem como objetivo fortalecer o processo de ensino-aprendizagem, criando condições 
para a permanência da/o estudante de baixa renda na instituição de ensino, permitindo que ele conclua seu curso dentro dos padrões de qualidade previstos.

As ações de atendimento universal também são desenvolvidas contemplando a todo e qualquer estudante do IFRN através da demanda espontânea. Assim, o apoio a complementação das atividades acadêmicas e a formação integral dos estudantes, e o apoio ao desenvolvimento acadêmico são ações universais da assistência estudantil.

O apoio a complementação das atividades acadêmicas e a formação integral das/os estudantes compreende a proteção, atenção e o pleno desenvolvimento escolar através de um atendimento universal, o qual é feito através de uma equipe multidisciplinar da assistência estudantil formada por profissionais das várias áreas do conhecimento, como assistentes sociais, fisioterapeutas, médicas/os, nutricionistas, odontólogas/os, psicólogas/os, e profissionais de enfermagem. Para isso cada campus do IFRN conta com um serviço de saúde composto por uma equipe habilitada a desenvolver atividades educativas individuais e coletivas e a prestar atendimentos ambulatoriais e assistenciais aos discentes no âmbito da atenção primária.

As ações de apoio psicossocial fazem parte de uma outra dimensão da assistência estudantil, interligando as áreas de Psicologia, Pedagogia e Serviço Social, com o objetivo de identificar as situações individuais e coletivas que interfiram ou venham a interferir negativamente na qualidade de vida, no desempenho acadêmico e na permanência da/o estudante na instituição, com o baixo rendimento acadêmico, uma das principais causas de evasão escolar. (IFRN, 2014)

Para detectar esses e outros problemas, são realizados atendimentos individuais e em grupo das/os estudantes e suas famílias, intervenções em sala de aula, palestras, orientações aos docentes, reunião de pais, além de orientação profissional aos estudantes e do acompanhamento de suas trajetórias estudantis. $O$ trabalho conjunto destes profissionais potencializa a identificação de situações de vulnerabilidades sociais para o devido encaminhamento aos profissionais que podem atuar na resolução dos problemas identificados. (IFRN, 2014) 
Desse modo, para promover e ampliar a formação integral da/do estudante, a assistência estudantil dispõe de ações que são desenvolvidas por meio de programas de caráter acadêmico, sociais, cultural, esportivo e político-estudantis. Referenciadas na perspectiva do direito de cidadania, essas ações são desenvolvidas em conjunto com as Pró-Reitorias de Ensino, Extensão e Pesquisa e Inovação, por meio da concessão de bolsas ou auxílios, para participação em aulas externas, em eventos científicos e em fóruns de ensino, além da promoção de eventos formativos (encontros e seminários), culturais, políticos, esportivos e de lazer voltados aos estudantes.

Ressalte-se que a Política de Assistência Estudantil no IFRN procura estimular a participação da/o discente nos espaços deliberativos e consultivos, como aspecto fundamental para a formação integral e cidadã, concretizando o direito a educação pública e de qualidade para todos. Para isso, valoriza e apoia os órgãos de representação estudantil no IFRN, como os Grêmios Estudantis, Diretório Central os Estudantes (DCE) e os Centros Acadêmicos (CA's).

Já no que diz respeito ao apoio a permanência e ao êxito escolar dos estudantes em situação de vulnerabilidade social, este é balizado por ações da assistência estudantil direcionadas aos grupos sociais prioritários.

No IFRN, a democratização do acesso por meio das ações afirmativas, como as cotas sociais e raciais, alterou significativamente o perfil dos estudantes nos diferentes níveis e modalidades de ensino ofertados pela instituição. A diversificação no perfil socioeconômico das/os estudantes pode ser verificada através de indicadores sociais como: renda per capita, etnia, zonas residenciais, faixa etária, procedência escolar, participação em programas sociais do governo federal, acesso aos serviços de saúde pública, entre outros.

Primeiramente, o acesso da/o estudante a instituição é viabilizado com a isenção da taxa do processo seletivo e analise de cotas; em seguida, a sua permanência no curso é estimulada por um conjunto de ações empreendidas pela Assistência Estudantil com vistas a promoção da igualdade de oportunidades entre todas/os as/os estudantes e contribuição para a melhoria do desempenho acadêmico e para a formação integral dos estudantes. 
Alinhadas aos objetivos do Programa Nacional de Assistência Estudantil (PNAES), criado pelo decreto ํㅜ 7.234, de 19 de julho de 2010, o qual visa buscar a garantia da permanência dos jovens nas instituições federais de ensino superior (IFES), propondo a promoção da inclusão social na educação e o Plano Nacional de Assistência Estudantil (PNAES/2007), o qual propõe buscar recursos necessários para aqueles estudantes em baixa condição socioeconômica, garantindo a estes permanência e, consequentemente conclusão em instituições federais de ensino superior.

Desse modo, estas ações são implementadas pelo Serviço Social por meio das bolsas de fomento aos estudos dos estudantes do PROEJA, iniciação profissional, alimentação e auxílio-transporte, e priorizam as/os estudantes pertencentes a grupos sociais específicos, quais sejam: oriundos de escola pública; famílias de baixa renda; principalmente os integrantes dos programas sociais do governo federal, pessoas com deficiência ou com necessidades educacionais especiais. (IFRN, 2014)

Diante do que foi exposto anteriormente, é notável que a existência de elegibilidade para a concessão de auxílios, bolsas e outros benefícios, não afasta o compromisso do Serviço Social de trabalhar sempre na perspectiva da universalidade do atendimento. Contudo, é indiscutivel afirmar que a constituição das politicas sociais ao longo do cenário brasileiro se dá por diversos processos de contradição, regressão e barbarie, uma vez que estas não se constituem em politicas propriamente ditas; ao contrário sao resultado de situações historicamente determinadas, de revoluçoes, crises economicas e de reivindicações operárias. Sendo assim, a politica de assistência estudantil vai ser afetada com este processo de enxugamento com os gastos sociais e consequentemente o Serviço Social fica com sua autonomia comprometida.

Portanto, nota-se que a assistência estudantil mesmo que tenha o objetivo de garantir o direito das/os estudantes ao acesso dos programas, esta é dotada de contradições e tensões, uma vez que o cenário é de seletividade ferrenha e de tremenda injustiça, pois a lógica que rege os programas é de selecionar "a/o pobre 
das/os mais pobres", e consequentemente há a exclusão de estudantes que também se encontram em vulnerabilidade social.

\section{O SERVIÇO SOCIAL NA DIGAE (Diretoria de Gestão de atividades estudantis)}

O Serviço Social do IFRN pode estar inserido na DIGAE (Diretoria de Gestão de atividades estudantis), COAES (Coordenação de atividades estudantis) ou DIAES (Diretoria de atividades estudantis). Esta atuação dependerá da particularidade do campus que este profissional estará inserido. Dessa maneira, a DIGAE está vinculada a reitoria e atualmente o quadro de profissionais do Serviço Social nessa Diretoria é composto por três assistentes sociais, uma está afastada para mestrado, outra atuando como Diretora de Gestão de Atividades Estudantis e uma atuando diretamente com as demandas que chegam.

A DIGAE tem como objetivo pensar, elaborar, implementar e avaliar a Política de Assistência Estudantil como instrumento de abertura e acesso aos direitos sociais para permanência das/os alunos na instituição, através de programas capazes de atender a demanda estabelecida em função de alunos que tenham um perfil socioeconômico sob o viés da vulnerabilidade. Inserindo-se no espaço de proposição de políticas públicas, o órgão compreende um espaço de coordenação e monitoramento de como se desenvolvem as atividades do Serviço Social de todos os campi do IFRN. Além disso, é válido ressaltar que a DIGAE trabalha em parceria com os campi para fazer um planejamento participativo e assim poder analisar mais fidedignamente a realidade da política de assistência estudantil e posteriormente colocar em prática as ações.

O Serviço Social no IFRN tem, ao longo dos anos, implementado ações, programas e projetos que vêm ao encontro das necessidades sociais de seus alunos, através de estratégias de acesso e permanência na Instituição, principalmente daqueles oriundos de classes menos favorecidas socioeconomicamente, contribuindo, assim, para a efetivação da educação como um direito social. 
Dessa forma, é desenvolvido um conjunto de ações realizadas através de programas e projetos específicos, tendo como princípio da assistência estudantil a proteção social, através do apoio, orientação, capacitação e inclusão nos diversos programas, identificando as demandas sociais apresentadas pelos estudantes.

A implementação dos programas vinculados à Assistência Estudantil no âmbito do IFRN está relacionada ao trabalho integrado de profissionais em atuação nas diversas áreas do conhecimento: serviço social, medicina, enfermagem, fisioterapia, nutrição, psicologia e odontologia.

Sendo assim, a atuação da/o assistente social na DIGAE é baseada no planejamento, acompanhamento, avaliação e orientação voltadas para a gestão de políticas da assistência estudantil com o objetivo principal de assegurar a permanência de estudantes em situações de vulnerabilidade socioeconômica por entender que estes têm maior probabilidade de evadir-se ou mesmo de retardar sua trajetória acadêmica devido a condições desfavoráveis que interferem concretamente no contexto escolar.

Assim, compete a DIGAE coordenar o programa de assistência estudantil do IFRN em consonância com os campi, promovendo o acesso e a permanência de alunas/os através da garantia de direitos sociais aos que não dispõe de condições socioeconômicas capazes de atendê-las/os em suas necessidades básicas de sustentação e educação.

\section{OPERACIONALIZAÇÃO DO PROCESSO DE ESTÁGIO SUPERVISIONADO}

Destaca-se o estágio supervisionado com um papel significativo no processo de formação profissional do estudante, uma vez que esse processo representa uma aproximação com a realidade cotidiana dos indivíduos sociais, associada à apropriação de conhecimentos teórico-metodológicos, norteadores do exercício profissional da/o assistente social (OLIVEIRA, 2004).

Dessa maneira, tem-se no processo de estágio um momento de relevância para as/os estudantes em formação, pois é diante da prática vivenciada que o 
estudante relaciona a teoria abarcada na academia, fazendo uma ponte entre teoriaprática e constatando que ambas são indissociáveis.

Logo, as atividades realizadas durante o processo de estágio na Diretoria de Gestão de Atividades Estudantis (DIGAE) são diversificadas e compreendem grande contribuição para o amadurecimento enquanto estudantes em formação profissional. Além do mais, foi diante dessa vivência que pude me apropriar das atividades executadas pelo serviço social.

Dentre as atividades, destacam-se as seguintes: participação em várias videoconferências para discussão do planejamento e regulamentos dos programas de assistência estudantil; acompanhamento das atividades relacionadas à gestão da política de atividades estudantis; participação em reuniões do setor e com as/os estudantes bolsistas atuantes na Reitoria; acompanhamento do rendimento acadêmico e da frequência escolar das/os alunas/os bolsistas de Iniciação Profissional da Reitoria; participação na realização de entrevistas para o também programa de Iniciação Profissional; auxílio na elaboração dos editais para os programas da assistência estudantil; atendimento aos campi através de contatos telefônicos para a retirada das mais variadas dúvidas; atualização do contato das Instituições que compõem a rede sócio assistencial da cidade do Natal; auxílio na verificação dos registros das atividades do serviço social mediante o SUAP; auxílio na elaboração do Plano de Desenvolvimento Institucional; subsídio na construção de memorandos e no envio de e-mails; participação em eventos que evolvessem o serviço social; acompanhamento da execução física e financeira dos campi; sistematização de informações em planilhas, atendimento aos estudantes; análise e seleção das fichas de inscrição de alunos candidatos a bolsa de Iniciação Profissional.

Tendo o estágio curricular obrigatório grande importância para a formação profissional da/o estudante, salienta-se que a materialização desse processo deve ocorrer em consonância com os princípios ético-políticos, contidos no código de ética dos assistentes sociais, que se constituem como valores norteadores do projeto profissional do serviço social brasileiro (ABEPSS, 2010). 
Em suma, nota-se que as atividades desenvolvidas no ambiente de estágio realizado estão em consonância com a lei de regulamentação da profissão, uma vez que essa propõe como atribuição privativa da profissão o explicitado no seu artigo 5, compreendendo as seguintes atribuições, por exemplo: I - coordenar, elaborar, executar, supervisionar e avaliar estudos, pesquisas, planos, programas e projetos na área de Serviço Social; $X$ - coordenar seminários, encontros, congressos e eventos assemelhados sobre assuntos de Serviço Social.

Portanto, cabe ao serviço social da DIGAE realizar o que é exposto na sua lei de regulamentação e assim o é desenvolvido, repassando atividades condizentes para os estagiários.

Destaca-se ainda que as atividades desenvolvidas no estágio estão de acordo com o código de ética de 1993 do serviço social, uma vez que no acompanhamento do dia-a-dia da assistente social e no que proposto para a execução ficaram nítidos alguns princípios do código: $\mathrm{V}$ - Posicionamento em favor da equidade e justiça social, que assegure universalidade de acesso aos bens e serviços relativos aos programas e políticas sociais, bem como sua gestão democrática; X - Compromisso com a qualidade dos serviços prestados à população e com o aprimoramento intelectual, na perspectiva da competência profissional;

Além disso, também se ressaltam artigos do código de ética ( $5^{\circ}$ e $8^{\circ}$ ), bem como: c) democratizar as informações e o acesso aos programas disponíveis no espaço institucional, como um dos mecanismos indispensáveis à participação dos usuários; a) programar, administrar, executar e repassar os serviços sociais assegurados institucionalmente.

Logo, é no desenvolvimento das atividades propostas que foi percebida a referente relação com os aportes legais da profissão, reafirmando que o fazer profissional nada mais é do que uma ponte com o aparato teórico estudado na academia e um comprometimento com o que compreende o projeto ético político do serviço social.

Em relação aos subsídios de educação, bem sabemos que estes referenciam a atuação do serviço social na DIGAE, refletindo na própria execução 
das atividades possibilitadas pela vivência de estágio. Portanto, cabe ao serviço social deter de uma concepção de educação emancipadora, que possibilite aos indivíduos o desenvolvimento de suas potencialidades e capacidades como gênero humano (CFESS, 2012). Além do mais, compete a essa/e profissional trabalhar na garantia do acesso e da permanência dos estudantes na Instituição. Porém, este termina submetido a uma prática burocratiza e submersos ao cotidiano profissional perverso e, portanto, não conseguindo realizar ações para além do dia a dia do gerenciamento dos programas da assistência estudantil.

Desse modo, foi diante a participação assídua nas mais variadas atividades do serviço social que consegui visualizar a relação dos afazeres da assistente social com o projeto ético-político da profissão, bem como perceber o comprometimento da profissional com o desenvolvimento do seu trabalho.

\section{DIFICULDADES, POTENCIALIDADES, DESAFIOS E APRENDIZAGENS APREENDIDOS E DESENVOLVIDOS AO LOGO DO PROCESSO DE ESTÁGIO.}

Compreende-se o estágio supervisionado em serviço social como um dos momentos em que o estudante estabelece a relação imediata entre o conhecimento teórico-metodológico e o trabalho profissional, a capacitação técnico operativa e o desenvolvimento de competências que norteiam o exercício profissional (ABEPSS, 2010).

Nessa perspectiva, tem-se o destaque assumido pelo estágio no processo de formação profissional das/os estudantes, tendo em vista que é durante essa vivência que os alunos vivenciam o espaço de tensões e contradições que norteiam o dia a dia profissional, bem como fazem uma relação com a carga teórica adquirida na Academia. Além do mais, a supervisão direta de um profissional na Instituição de estágio juntamente com um docente da Universidade é de grande relevância para que o estudante tenha mais tranquilidade no seu processo de ensino-aprendizagem, bem como consiga proceder nas suas ações de forma menos tensionada.

Assim, o estágio no IFRN- Reitoria, mais especificamente no setor da DIGAE, nos possibilitou abarcar uma gama de conhecimentos, adentrando no dia a 
dia do serviço social na Instituição, bem como partilhando das suas angústias, determinação, firmeza, comprometimento com os seus usuários, aprimoramento intelectual e compromisso com o projeto ético político da profissão. Por isso, tendo em vista, a riqueza que o próprio estágio possibilita aos estudantes de serviço social e o contato com os mais diversos profissionais da categoria, suas diversas formas de atuação, podemos afirmar que a vivência desse processo é satisfatória e positiva para o crescimento e amadurecimento enquanto futuras assistentes sociais.

Ressalta-se ainda o contato com uma das áreas de atuação do serviço social, a educação, na qual o mesmo é convocada/o a atuar nas expressões da questão social, mas, sobretudo tem competência de planejar, propor, elaborar, coordenar e executar ações, projetos e programas sociais na ampla realidade social e institucional (AMARO, 2012). Além do mais, tivemos aproximação com a área da gestão, na qual o serviço social também é chamado a atuar e pudemos perceber que sua atuação é tão importante quanto à desenvolvida nos campi, pois é partindo do direcionado assumido pela gestão que os demais polos poderão desenvolver de forma ainda mais eficaz o seu trabalho.

O Programa Nacional de Assistência Estudantil (PNAES) é posto em prática no IFRN com vistas a garantir a permanência das/os estudantes no Instituto. Nessa linha, são caracterizados os programas da assistência estudantil (Auxílio Transporte, Iniciação Profissional e Auxílio Alimentação), coordenadas/os pelas/os assistentes sociais. Todavia, apesar da importância do acompanhamento aos programas, o que foi observado é que as/os assistentes sociais imersos nesse cotidiano profissional rotineiro e imediatista terminam voltando a sua prática exclusivamente para 0 gerenciamento desses programas assistenciais, não havendo a promoção de ações socioeducativas e um acompanhamento eficaz da/o aluna/o assistido. Além disso, percebeu-se a não existência de uma equipe multidisciplinar, o que tem interferido também no desenvolvimento do seu trabalho.

A existência na reitoria de apenas uma sala para várias/os profissionais como nutricionista, secretária/o e serviço social tem interferido na predominância do sigilo profissional, garantido pelo código de ética de 1993. Logo, as/os bolsistas que necessitam conversar com a/o assistente social de forma mais sigilosa são 
dirigidas/os para a sala da diretoria, quando esta não se encontra ou redirecionado para o corredor da Instituição por não haver uma sala exclusiva do assistente social para essa conversa.

Em suma, um grande desafio assumido foi compreender todo esse cenário de funcionamento no IFRN, mas, sobretudo perceber o papel da/o assistente social dentro desse Instituto e que estava direcionada para a reitoria e, portanto, assumiria dentro da DIGAE funções diferenciadas dos demais campi, tendo em vista que aqui o serviço social é direcionado para o acompanhamento, orientação, avaliação, planejamento e regulamentação dos programas de assistência estudantil. Estaria em contato com a área da gestão e, portanto, atividades cabíveis ao serviço social nesse âmbito.

Destarte, posso afirmar que houve um crescimento no processo de formação, pois o contato com a realidade, com aqueles conteúdos que passamos longos semestres estudando na Universidade se tornaram cada vez mais visíveis no dia- a- dia profissional, levando-nos a constatar que a teoria está nitidamente presente na prática profissional e ambas se complementam.

Contudo, mesmo sabendo que o processo de estágio é primordial para as/os estudantes estamos vivenciando nesse momento um governo que vai na contramão dos direitos das/dos trabalhadoras/es, com posicionamentos fascistas e genocidas quando não se preocupa com a formação profissional das/dos estudantes lançando a portaria MEC № 343 , de 17 de março de 2020, que dispõe sobre a substituição das aulas presenciais por aulas em meios digitais enquanto durar a situação de pandemia do novo coronavírus (COVID-19).

A proposta de realização online das atividades desconsidera a excepcionalidade da situação e que radicalmente modifica a dinâmica de vida de docentes e discentes na qual todos os membros familiares se encontram em casa, trazendo sobrecargas particularmente às mulheres (maioria do nosso corpo discente e docente); desconsidera as formas de acesso à internet dos discentes mais pobres; desconsidera a dimensão pedagógica que a relação presencial possibilita no processo formativo; e desconsidera as dimensões sociais e psicológicas de 
adaptação à nova realidade. Os elementos listados são importantes no processo ensino-aprendizagem. (ABEPSS,2020)

Desse modo, a ABEPSS no exercício da autonomia universitária e considerando as respectivas particularidades, afirma que as universidades têm respondido de diferentes formas às orientações de suspensão das atividades no combate ao Coronavírus (COVID 19): adiamento do início do período letivo, suspensão do calendário acadêmico, postergação das atividades para o segundo semestre de 2020. A ABEPSS avalia como acertadas, as medidas suspensivas, que, consequentemente interrompem também a Supervisão Acadêmica realizada por assistentes sociais docentes, no exercício da atribuição privativa de Supervisão Direta de Estágio.

\section{CONSIDERAÇÕES FINAIS}

O cotidiano no qual as/os assistentes sociais estão inseridos é invadido pela heterogeneidade, espontaneidade, imediaticidade e superficialidade extensiva, tornando o dia-a-dia profissional rotineiro e pragmático. Todavia, é necessário que as/os profissionais intervenham no seu próprio dia a dia fugindo do que se coloca e propondo ações que intervenham na realidade.

A experiência de estágio como salienta Guerra (2012), permite a capacitação das/os estudantes para que venham a investigar o campo, analisá-lo criticamente, problematizar o contexto sócio-institucional e o significado sóciohistórico do trabalho e pensar nas estratégias de enfrentamento a resistência.

É nessa perspectiva que se ressalta a grande importância do estágio para o processo de formação e amadurecimento profissional. Assim, o estágio no IFRNreitoria nos possibilitou apreender diferentes concepções sobre o cotidiano profissional e as/os assistentes sociais que o formam, bem como o trabalho desenvolvido por estes nesta Instituição.

Ademais, se constata os programas da assistência estudantil e suas contradições, pois estes não conseguem abarcar todas/os os estudantes que estão em situação de vulnerabilidade social, tendo em vista que as vagas ofertadas não 
são suficientes, havendo sempre a demanda maior do que a oferta. Logo, as/os assistentes sociais são levados a excluir seus próprias/os usuárias/os, utilizando assim para a sua inserção o critério de quem mais necessitar.

Portanto, o cotidiano é perverso e contraditório, porém precisamos de profissionais que não se deixam invadir por esse dia a dia e são comprometidas/os com o projeto ético político da profissão, buscando melhores alternativas para a promoção de um trabalho eficaz e de qualidade para os seus usuários.

No cotidiano da DIGAE foi visualizado uma profissional comprometida com as/os suas/eus usuárias/os, lutando pela garantia dos seus direitos, que é responsável nas suas atividades, conhece os aportes legais da profissão, busca está em constante atualização de conhecimentos, é firme nos seus direcionamentos e nos permitiu ao longo do estágio crescer enquanto futuras assistentes sociais, pois ocorreu uma troca de conhecimentos entre profissional-estagiárias e a aquisição de mais amadurecimento e conhecimento diante das demandas, relação com os usuários e demais profissionais.

Assim, o estágio supervisionado foi de suma importância para o processo de ensino-aprendizagem, levando a compreender que existem muitos desafios para haver a aplicação de forma mais ampla do projeto ético-político, tendo em vista a existência de muitos limites no cotidiano profissional. Todavia, foi possível perceber a necessidade da formação de profissionais críticos, cada vez mais comprometidos com os seus usuários. Além disso, a/o assistente social deve prezar pela articulação entre as três dimensões da profissão, a teórico-metodológica, técnico-operativa e ético-política, caracterizando desse modo um fazer profissional de qualidade.

\section{REFERÊNCIAS}

\section{ABEPSS. Política nacional de estágio da associação brasileira de ensino e pesquisa em serviço social - ABEPSS. 2010.}

ABEPSS. Nota referente ao estágio supervisionado no período de isolamento social para o combate ao novo coronavírus (COVID 19) - ABEPSS. 2020. 
AMARO, Sarita. Serviço social na educação: bases para o trabalho profissional. Florianópolis. Ed. da UFSC, 2012.

BARROCO, Maria Lucia Silva; TERRA, Sylvia Helena. Código de ética comentado. Conselho Federal de Serviço Social - CFESS - São Paulo: Cortez, 2012.

BRASIL. Lei de Regulamentação do serviço social. Disponível em:

http://www.planalto.gov.br/ccivil 03/leis/L8662.htm Acesso em: 21 de maio. 2015

BRASIL. Programa Nacional de Assistência Estudantil. Disponível em: http://www.planalto.gov.br/ccivil 03/ Ato2007-2010/2010/Decreto/D7234.htm Acesso em: 21 de maio. 2015

\section{CFESS. Subsídios para a atuação de assistentes sociais na política de} educação. 2012.

GUERRA, Yolanda ett all. A dimensão técnico-operativa do serviço social: desafios contemporâneos. Editora da UFJF. 2012.

IAMAMOTO, Marilda Vilela. Serviço Social em tempo de capital fetiche: capital financeiro, trabalho e questão social/ Marilda Vilela lamamoto- $4^{\mathrm{a}}$ ed. - São Paulo: Cortez 2010.

INSTITUTO FEDERAL DE EDUCAÇ̃̃O, CIÊNCIA E TECNOLOGIA DO RIO GRANDE DO NORTE. Resolução no 23 de 17 de dezembro de 2010. Aprova o Plano de Assistência Estudantil do Instituto Federal de educação, ciência e tecnologia do Rio Grande do Norte. Dezembro, 2010. Disponível em:<http://portal.ifrn.edu.br/cons.../consup/resolucoes/resolucoes2010/Resolucao\%2023-2010.pdf/view>. Acesso em: 13 de nov. 2014

OLIVEIRA, Cirlene Aparecida Hilário da Silva. O estágio supervisionado na formação profissional do assistente social: desvendando significados. Revista Serviço Social \& Sociedade. São Paulo, 2004. 